Check for updates

Madrid, Spain

Cite this as: BMJ 2021;375:n3085 http://dx.doi.org/10.1136/bmj.n3085 Published: 14 December 2021

\section{Covid-19: Almost 100 ICU staff from Malaga hospital test positive after Christmas lunch}

\section{Aser García Rada}

Several healthcare organisations in Malaga, Spain, have cancelled all Christmas social events after nearly 100 staff from a local hospital became infected with covid-19 following a festive lunch.

Most of those who attended the lunch on 1 December work in the intensive care unit (ICU) at Málaga Regional University Hospital, a 57 bed facility with more than 400 staff.

Jesus Aguirre, the regional minister of health and families, said in a press conference on 10 December that there were already 96 confirmed cases related to the event, including workers-most of them nurses or nurse aides-and some relatives, although none have required hospital admission.

“Those with symptoms have very mild ones," a hospital spokeswoman told The BMJ. "They were vaccinated against covid-19, most of them with a third dose," she said, and many are returning to work this week. The ICU service has not been affected and shifts have been covered by new hires and by some staff who have "volunteered to do double shifts," she said.

Many other departments of the hospital, as well as the College of Physicians of Malaga and the Public Company of Health Emergencies which manages the regional emergency hotline, have cancelled all Christmas social activities following the outbreak.

Some 170 ICU professionals attended the lunch at a restaurant in the Teatinos neighbourhood of Málaga, although the party swelled to more than 200 people by late evening. All guests were required to have a negative lateral flow test to attend, but some began to present covid-19 related symptoms on 4 December.

It remains unclear where the infections originated, but on 28 November many of the guests had taken a public exam for the regional health service, although windows in the exam hall at Málaga University were kept open for ventilation. Many of the 4000 taking the exam went to nearby bars afterwards, according to the newspaper El País. "We think that's the key-all those people spending the afternoon without masks inside bars in the area," a nurse told El País.

Following criticisms on some media platforms, the CSIF union, which represents many public employees, released a statement saying it was "very unfair" to criminalise healthcare workers who have "not violated any rule or skipped any type of restriction."

In Spain, using face masks is mandatory in public places but regional regulations do not extend to bars or restaurants.

The College of Physicians of Malaga released a statement in support of the affected workers saying, "Thanks to the vaccine, the symptoms of those that have tested positive are very mild and, in many cases, they remain asymptomatic." 